\title{
Antibióticos: ¿enemigos o aliados?
}

\author{
Ana Molinero \\ Vicepresidenta de SEFAC.
}

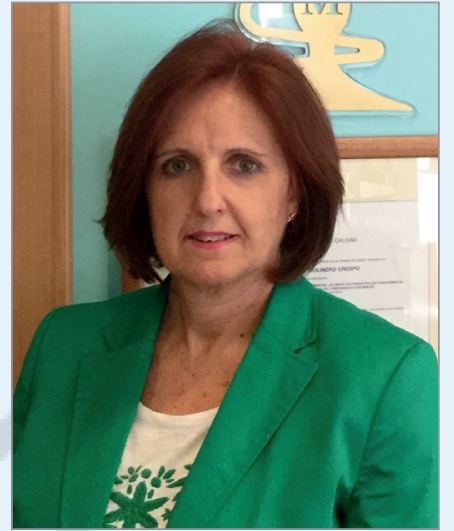

Ana Molinero
En la década de 1920, Alexander Fleming descubrió, por casualidad, una sustancia que podía atacar a ciertas bacterias. Años más tarde, observó que colonias de la bacteria común Staphylococcus aureus eran eliminadas por un moho que había crecido en la misma placa Petri, determinando que este moho (Penicillium) elaboraba una sustancia, a la que llamó penicilina, que podía disolver las bacterias. Sus resultados se publicaron en 1929 [1] y se comenzó a utilizar en la práctica clínica en la década de los años 1940. Con la aparición de la penicilina se dio comienzo a la era de los antibióticos.

Los antibióticos han sido el mayor descubrimiento médico de la historia de la medicina: curan enfermedades que hasta principios del siglo pasado eran mortales. Antes de su descubrimiento el 90\% de los niños que padecían una meningitis bacteriana morían y los que sobrevivían padecían discapacidades graves, sordera o retraso mental; las infecciones de garganta y otras infecciones como la tuberculosis, neumonía o tosferina, provocaban normalmente la muerte [2]. Además han contribuido de forma significativa al progreso en campos como los trasplantes de órganos sólidos $\mathrm{y}$ de progenitores hematopoyéticos, la supervivencia de prematuros e inmunodeprimidos, la cirugía de material protésico y los catéteres vasculares, donde las infecciones son especialmente prevalentes e importantes [3].

Sin embargo, han generado también el mayor problema médico de la historia [4], ya que desde el comienzo de su uso, la resistencia bacteriana a los antibióticos ha pasado de ser una amenaza a ser una realidad. Se estima que en la Unión Europea se producen 25.000 muertes al año por infecciones resistentes a antibióticos (2.500 en España). La sobreutilización de antibióticos es un factor determinante del aumento de las infecciones resistentes a antibióticos. En Estados Unidos se estima que el 30\% de las prescripciones de antibióticos pueden haber sido innecesarias [5]. En España, entre el 40 y el 50\% de las prescripciones de antibióticos que se realizan en los servicios de atención primaria y hospitalaria son inadecuadas, según la Agencia Española de Medicamentos y Productos Sanitarios (AEMPS).

La Comisión Europea ha realizado encuestas sobre el grado de conocimiento y uso de los antimicrobianos por la población general, publicando los resultados en el denominado Eurobarómetro Especial sobre Resistencias Antimicrobianas. El informe, de abril 2016 [6], arroja unos resultados para la reflexión. Mientras que en la mayoría de los países se ha disminuido el consumo de antibióticos, en España ha aumentado un 9\%, aunque hemos bajado dos puntos porcentuales para situarnos en el 6\% con respecto al Eurobarómetro de 2013 en su consumo sin receta. Los mayores consumos se asocian con un menor nivel cultural y con un bajo estatus económico. $Y$ aunque hemos mejorado 8 puntos desde 2013 en lo que se refiere al conocimiento sobre la eficacia de los antibióticos frente a los virus, seguimos estando por debajo de la media europea. Lo mismo nos ocurre cuando la pregunta se refiere a la eficacia frente a la gripe o resfriado. Sin embargo, nuestro conocimiento sobre la aparición de resistencias cuando se realiza un mal uso de los mismos es similar a la media europea y se sitúa en el 85\%.

Pero como farmacéuticos comunitarios nos debe preocupar, además, que solo un $6 \%$ de los farmacéuticos comunitarios ofreció información acerca de no tomar antibióticos de manera innecesaria (4 puntos menos de la media europea), que solo el 23\% de los encuestados preguntaría a un farmacéutico para obtener información fiable sobre antibióticos (14 puntos por 
debajo de la media europea) y que el $42 \%$ de la población no quiere recibir ningún tipo de información sobre los temas relacionados con los antibióticos.

La AEMPS preocupada, con anterioridad a la publicación de estos datos, por el buen uso de los antibióticos realizó en marzo de 2016 una reunión dentro del marco del proyecto ARNA [7] (Antimicrobial Resistance and causes of Non-prudent use of Antibiotics in human medicine in the EU), financiado por la Comisión Europea, en la que participó SEFAC junto a otras sociedades científicas, responsables de política sanitaria, representantes de organizaciones colegiales y representantes de organizaciones de consumidores. Este proyecto nació para ayudar y contribuir a un uso más prudente de los antibióticos en medicina humana en Europa, focalizándose en el consumo de antibióticos sin prescripción médica y la automedicación. El objetivo principal de dicho proyecto es evaluar estas situaciones para fomentar políticas que conduzcan a un uso prudente de los antibióticos.

En esa reunión se trabajó sobre tres grandes bloques:

1. Medidas para hacer frente a la prescripción y dispensación de antibióticos cuando no están indicados.

2. Medidas para hacer frente al almacenamiento de antibióticos en casa y al uso de estos antibióticos sobrantes (procedentes de anteriores prescripciones).

3. Fortalecer la posición de los profesionales sanitarios para que se sientan menos presionados por los pacientes en la toma de decisiones relativas a la prescripción y dispensación de antibióticos.

Y se consensuaron recomendaciones en tres niveles de intervención: campañas de salud pública, profesionales sanitarios, y política y legislación sanitaria.

En el día a día en la farmacia comunitaria no basta con dedicar un día (18 de noviembre de cada año) al "Uso Prudente de los Antibióticos” y realizar una campaña puntual, sino que hay realizar una labor continuada, ya que el farmacéutico comunitario representa el primer eslabón de la cadena de asistencia sanitaria en muchas ocasiones, incluso algunas veces el único, y es el último agente de salud que ve el paciente antes de iniciar una terapia farmacológica.

El farmacéutico comunitario, junto al resto de los profesionales sanitarios, debe educar a la población sobre el uso racional de los antibióticos, sobre los riesgos de las resistencias bacterianas y sobre los problemas de salud pública que pueden ocasionarse por el uso indebido de los mismos, problemas que van más allá de la salud individual.

Debe insistir también en la importancia del cumplimiento terapéutico y desarrollar estrategias para aumentar la adherencia terapéutica, a la par de informar sobre la importancia de no utilizar antibióticos sobrantes de otras ocasiones y de depositar en el punto SIGRE la medicación antimicrobiana no utilizada en un proceso infeccioso. A esto contribuiría también bastante mejorar todavía más la adecuación de los formatos de los medicamentos a los días reales de tratamiento.

La realización de un servicio profesional farmacéutico de indicación farmacéutica, utilizando protocolos de actuación desarrollados junto a sociedades científicas médicas, o la utilización de herramientas de trabajo para discernir entre infecciones víricas o bacterianas sería de gran utilidad a la hora de evitar un uso inadecuado de los antibióticos, como ya se ha demostrado en experiencias previas llevadas a cabo por SEFAC (Streptotest).

Por último, la formación conjunta de todos los profesionales sanitarios implicados fomentando la importancia de la receta médica como elemento previo al consumo de antibióticos y no banalizando su utilización ayudaría a que el paciente no presionase el médico para la prescripción o al farmacéutico para la dispensación.

SEFAC, además, va a iniciar un estudio nacional para la AEMPS -Demanda de antibióticos en farmacia comunitaria con receta privada, prescripción irregular y sin prescripción (automedicación): intervención del farmacéutico- cuyos resultados podrán ser de gran utilidad para implementar estrategias que conduzcan a un mejor uso de los antibióticos y a frenar las resistencias bacterianas. Como sociedad científica creemos que este trabajo puede ser una gran oportunidad para demostrar el valor sanitario de los farmacéuticos comunitarios y esperamos en que haya una participación activa por parte del colectivo como muestra de su compromiso en el abordaje de este problema sanitario tan relevante.

El que los antibióticos sean nuestros aliados y no nuestros enemigos está, en parte, en nuestra mano. ¿Hacia qué lado nos queremos inclinar?

\section{Referencias bibliográficas}

1. Fleming A. On the Antibacterial Action of Cultures of a Penicillium with Special Reference to their Use in the Isolation of B. influenzae. Br J Exp Pathol. 1929; 10(3):226-236.

2. Lozano R, Naghavi M, Foreman K, Lim S, Shibuya K, Aboyans $\mathrm{V}$, et al. Global and regional mortality from 235 causes of death for 20 age groups in 1990 and 2010: a systematic analysis for the Global Burden of Disease Study 2010. Lancet. 2012; 380:2095-2128.

3. Pagalilauan GL, Limaye AP. Infections in transplant patients. Med Clin North Am. 2013; 97:581-600. doi:10.1016/j. mcna.2013.03.002

4. González-Zorn B. Resistencias a Antibióticos: Vuelta al siglo XIX. Jornada del Día Europeo para el Uso Prudente de los Antibióticos. Madrid: Agencia Española de Medicamentos y Productos Sanitarios; 2015. [Consultado 29/08/2016]. Disponible en: https://www.aemps.gob.es

5. Fleming-Dutra KE, Hersh AL, Shapiro DJ, Bartoces M, Enns Eva A, Files Jr TM et al. Prevalence of Inappropriate Antibiotic Prescriptions Among US Ambulatory Care Visits, 2010-2011. JAMA. 2016; 315(17):1864-1873. doi:10.1001/ jama.2016.4151

6. Special Eurobarometer 445: Antimicrobial Resistence. Survey requested by the European Commission, Directorate-General for Health and Food Safety and co-ordinated by the Directorate-General for Communication. European Union; 2016. [Consultado 29/08/2016]. Disponible en: http://ec.europa.eu/COMMFrontOffice/PublicOpinion/index.cfm/Survey/ getSurveyDetail/search/Antimicrobial\%20Resistance/surveyKy/2107

7. Antimicrobial resistance and causes of non-prudent use of antibiotics in human medicine (ARNA Project). The Netherlands; 2016. [Consultado 29/08/2016]. Disponible en: https://www. nivel.nl/en/arna 